\title{
Correlates of Weight Instability across the Lifespan in a Population-Based Sample
}

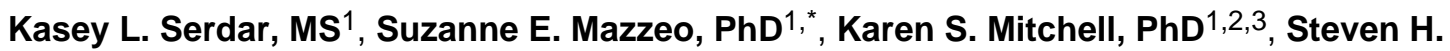 \\ Aggen, $\mathrm{PhD}^{2,4}$, Kenneth S. Kendler, $\mathbf{M D}^{2,4}$, and Cynthia M. Bulik, PhD ${ }^{5,6}$ \\ ${ }^{1}$ Department of Psychology, Virginia Commonwealth University, Richmond, Virginia \\ ${ }^{2}$ Virginia Institute of Psychiatric and Behavioral Genetics, Richmond, Virginia \\ ${ }^{4}$ Department of Psychiatry, Virginia Commonwealth University, Richmond, Virginia \\ ${ }^{5}$ Department of Psychiatry, University of North Carolina at Chapel Hill, North Carolina \\ ${ }^{6}$ Department of Nutrition, University of North Carolina at Chapel Hill, North Carolina
}

\begin{abstract}
Objective-Research from overweight/obese clinical samples links weight instability to poor health. This study investigated whether negative health outcomes were associated with weight instability in a population-based sample.
\end{abstract}

Method-One thousand five hundred ten women and 1,111 men from the Mid-Atlantic Twin Registry completed questionnaires assessing demographics, body size in childhood, adolescence, and adulthood, health satisfaction, and disordered eating. Noneating disorder psychiatric diagnoses were assessed via clinical interviews.

Results-Weight instability was related to lower health satisfaction and self-esteem, and higher body dissatisfaction, dieting, and binge eating for both sexes. Weight unstable women were more likely to meet criteria for lifetime major depressive disorder, generalized anxiety disorder, and eating disorders. Weight stable women were more likely to abuse alcohol; however, two of these associations [e.g. weight instability and generalized anxiety disorder (GAD) and weight stability and alcohol abuse] became non-significant once lifetime binge eating was accounted for, indicating that these forms of psychopathology are more strongly related to binge eating than weight instability itself. No associations between weight stability and psychiatric diagnoses were found in men.

Discussion-Weight instability is related to mental and physical health concerns for both sexes. It was also specifically associated with depression and eating pathology in women.

\section{Keywords}

weight instability; binge eating; silhouette measures

\footnotetext{
(C) 2010 by Wiley Periodicals, Inc.

"Correspondence to: Dr. Suzanne Mazzeo, Department of Psychology, Virginia Commonwealth University, Richmond, Virginia. semazzeo@vcu.edu.

${ }_{3}^{3}$ Present address: National Center for Posttraumatic Stress Disorder, Women's Health Sciences Division, VA Boston Healthcare System, Boston University School of Medicine, Boston, Massachusetts
} 


\section{Introduction}

Weight cycling, or chronic weight loss and regain, ${ }^{1}$ is a common phenomenon, ${ }^{2-5}$ with some studies reporting that up to $75.9 \%$ of women lose and subsequently regain a significant amount of weight ( $10 \mathrm{lbs}$. or more) over a 5 -year period. ${ }^{5}$ This cycling appears to be related to adverse health outcomes, including eating pathology, ${ }^{4,6-9}$ although findings are mixed. Studies of repeated weight change have examined a limited time range, $3,5,7,9-11$ and most have included exclusively overweight individuals seeking weight-loss treatment. ${ }^{10}$ This sampling issue is noteworthy, as overweight individuals seeking treatment appear to differ systematically from nontreatment-seeking overweight individuals. ${ }^{12}$ In particular, higher rates of binge eating are reported in clinical samples. ${ }^{13}$

Further, most research on weight change has focused on women, despite findings indicating that eating pathology (particularly binge eating) is prevalent among men who manifest frequent weight changes. ${ }^{14}$ Moreover, given different societal weight ideals for men and women, ${ }^{15-17}$ there might be important sex differences in the correlates of weight cycling. ${ }^{14}$ Thus, the aim of the current study was to examine the psychological and health-related correlates of weight cycling across the lifespan in a population-based sample of men and women.

\section{Weight Cycling and Weight Instability}

Weight cycling is most often defined as repeated episodes of weight loss and regain. ${ }^{1}$ There is a lack of consensus regarding the specific criteria (amount of weight lost and regained, number of cycles, intentionality of weight loss) that distinguish weight cyclers from weight stable individuals. Some have defined weight cycling relatively stringently, ${ }^{5}$ requiring three or more cycles during which at least $10 \mathrm{lbs}$ were intentionally lost and subsequently regained. Others have required only one or two cycles of weight loss and regain. ${ }^{2}$ Further, some studies ${ }^{7,10}$ did not specify a number of cycles needed to meet their definition of weight cycling.

The impact of weight cycling on normal weight individuals is not well understood. Research has generally excluded normal weight individuals because definitions of the weight cycling construct have required that large amounts of weight are lost and regained, ${ }^{5}$ a criterion more likely to be met by overweight or obese individuals than those of normal weight. However, normal weight individuals experience weight cycling, but at a less extreme level than do overweight or obese individuals. ${ }^{10}$ This focus on overweight or obese individuals could confound estimates of disordered eating among those whose weight cycles, as bulimia nervosa (BN) often occurs in individuals of normal weight. ${ }^{18,19}$

The definition of weight instability used in this study addressed these limitations, and facilitated examination of a broader time period than previously investigated. In the current study, lifespan weight instability was assessed using silhouette measures representing participants' perceptions of their weight and shape in childhood, adolescence, and adulthood. This broader focus on weight patterns throughout the lifespan could yield valuable information about the long-term effects of weight loss and regain. The following 
sections briefly review the correlates of weight cycling, highlighting the public health significance of this issue.

\section{Correlates of Weight Cycling}

Medical-Repeated weight loss and regain is associated with numerous health problems, including cardiovascular disease, hypertension, Type II diabetes, ${ }^{20,21}$ decreased longevity, ${ }^{22,23}$ and obesity. ${ }^{24}$ Weight cycling individuals also report more negative health attitudes, more frequent doctor visits, and more sick time from work than their non-weight cycling peers. ${ }^{2,6}$

Dieting and Weight Control-Weight cycling is also associated with chronic dieting and long-term weight gain. ${ }^{9,25}$ Weight cycling individuals initiate dieting at a younger age and at a lower weight than weight stable individuals. ${ }^{25}$ Weight cyclers are also prone to higher rates of long-term weight gain compared with nondieting and weight stable individuals. ${ }^{9}$ These data are concerning given the rising prevalence of obesity in Western society ${ }^{26}$ and the poor outcomes of nonsurgical obesity treatment in adults. ${ }^{27}$ Thus, there is a need for research examining factors that might increase obesity risk, such as weight cycling.

Psychosocial Distress-Although findings are mixed, weight cycling is linked to several negative psychosocial outcomes. Weight loss and regain is associated with obesity, which, in turn, is associated with body dissatisfaction ${ }^{28-30}$ and low self-esteem. ${ }^{31-41}$ Further, weight cycling is associated with eating pathology, particularly binge eating. ${ }^{6,8,13,42,43}$ Most studies have not found an association between weight cycling and other (i.e. noneating disorder) psychiatric diagnoses. ${ }^{6,25}$ However, these investigations have assessed only a few diagnoses, most commonly depression. Moreover, many studies involved small clinical samples. ${ }^{6,11}$ Thus, additional research is needed to explore whether psychiatric problems are a significant issue in population-based samples of weight cycling individuals.

\section{Weight Change over the Lifespan}

In addition to understanding correlates of clinically significant weight cycling, it is important to identify normal patterns of weight change over the lifespan, to facilitate operationalization of the weight cycling construct. For most people, body weight is unstable over time. ${ }^{44,45}$ For example, one study ${ }^{45}$ found that four of nine participants in a group defined by the researchers as "weight stable" actually manifested weight fluctuations of more than $2.3 \mathrm{~kg}$ once or twice across three data collection points in a 1-year period. This indicates that some degree of natural weight fluctuation probably exists in the general population. However, it remains unclear how researchers should distinguish between natural variations in weight and the cycles of weight loss and regain seen among weight cyclers.

\section{The Use of Figural Stimuli in the Examination of Weight and Body Image}

Figural ratings can facilitate the assessment of weight change over the lifespan. This type of measure asks individuals to select a silhouette representing both their current and ideal body size from a series of images ranging from underweight to overweight. Silhouettes have been widely used since their introduction and yield stable and valid scores. ${ }^{46}$ Although these measures are not without critics, ${ }^{47}$ they are particularly useful in large epidemiological 
studies, as they are both easy to administer in a self-report format, ${ }^{46,48}$ and are highly correlated with measured BMI. ${ }^{49}$ Silhouettes also facilitate retrospective weight recall. In a study of elderly individuals, Must et al. ${ }^{50}$ found that individuals' selections of silhouettes that represented their body size at ages 10 and 15 years correlated well with their measured adolescent BMI.

\section{Summary and Hypotheses}

This study explored the physical and psychological characteristics of weight stable and unstable women and men from a population-based sample. Participants were classified as weight stable or weight unstable based on the degree of silhouette change exhibited across childhood, adolescence, and adulthood. We hypothesized that weight instability would be positively associated with health limitations, body dissatisfaction, drive for thinness, disinhibition, hunger, and binge eating, and would be negatively associated with general health attitudes. In addition, we proposed that psychiatric diagnoses [alcohol abuse/ dependence, generalized anxiety disorder (GAD), lifetime major depressive disorder (MDD), and panic disorder] would be associated with weight instability only when accompanied by a diagnosis of BED.

\section{Method}

\section{Participants}

Participants were from the population-based Virginia Twin Registry, ${ }^{51}$ which constitutes part of the Mid-Atlantic Twin Registry (MATR). These twins were born between 1934 and 1974 and were eligible if both individuals had previously responded to a mailed questionnaire, which yielded a response rate of approximately $64 \%$ for women and $32.6 \%$ for men. Between 1988 and 1997, twins from this study were approached four times for personal interviews. Questionnaires were mailed to prior participants in late 1999, although limited resources were available for follow-up (primarily phone calls to nonresponsive twins whose sibling had responded). The current study focuses on female $(N=1,510)$ and male $(N$ $=1,111$ ) twins who responded to the last wave of data collection. All participants were White, reflecting the ethnic composition of the MATR at the time of data collection.

\section{Measures}

All the following data (with the exception of the self-esteem and health behaviors measures and SCID interviews described below) were collected during the 1999 wave of data collection.

Demographic Questionnaire-Participants reported their age, education (in years), parents' education (in years), marital history, and current height and weight (used to calculate BMI and determine weight classification).

Figural Stimuli-Silhouettes based on Stunkard's standard silhouettes ${ }^{48}$ assessed participants' body image and size during childhood, adolescence, and adulthood. Participants selected their current and ideal size from a series of nine silhouette drawings ranging from very thin (number one) to very large (number nine) for each time period. 
Silhouettes were used instead of BMI to define weight instability because it was reasoned that individuals would be able to estimate more accurately their body silhouette for childhood and adolescence rather then their actual height and weight at these developmental periods. Further, epidemiological research has shown that silhouettes effectively identify both thin and obese individuals. ${ }^{49}$

Disordered Eating Attitudes and Behavior-The body dissatisfaction and drive for thinness subscales of the Eating Disorder Inventory (EDI) were used to assess disordered eating symptomatology. ${ }^{52}$ Modifications were made to the male version of the EDI to adapt for gender bias. An abbreviated version of the Three Factor Eating Questionnaire (TFEQ ${ }^{53,54}$ ) was also used to assess disordered eating and attitudes. This measure has three subscales, including dietary restraint, disinhibition, and susceptibility to hunger. It has yielded internally consistent scores (Cronbach's $[$ alpha $]=0.88$ ). ${ }^{55}$ A detailed description of this measure is available in Mazzeo et al. ${ }^{55}$ Of note, one item from each subscale of the TFEQ was dropped from the current analyses because inclusion of these items resulted in large amounts of missing data. These items assessed dieting behavior and were not answered by individuals if they did not diet.

Eating Disorders-Participants also answered dichotomous questions ("yes/no") regarding whether they had ever dieted or binged. They also completed items adapted from the SCID-I, ${ }^{56}$ which assessed anorexia nervosa (AN), bulimia nervosa (BN), and BED criteria as outlined in the Diagnostic and Statistical Manual of Mental Disorders, 4th edition (DSM-IV) ${ }^{57}$ Scores on these items were entered into diagnostic algorithms developed to assess whether participants met $D S M-I V$ criteria (for a full description of these criteria, please refer to Mazzeo et al. ${ }^{58}$ ).

Health Behaviors and Satisfaction-Health behaviors and satisfaction were assessed using a brief survey which included questions about health satisfaction and health limitations, as well as number of work days missed because of illness within the past year.

Rosenberg Self-Esteem Scale (RSE)—The RSE is a 10-item measure of selfesteem ${ }^{59}$; higher scores are indicative of lower self-esteem. The RSE yields stable and internally consistent scores, with Cronbach's [alpha] ranging from $0.73^{59}$ to $0.78 .{ }^{60}$ This measure was completed during a previous wave of data collection. ${ }^{61,62}$

Psychiatric Diagnoses-Data regarding lifetime psychiatric and substance use diagnoses were obtained from interviews conducted during previous waves of data collection, which were conducted by qualified and trained interviewers (full information regarding interviewer training and qualification has been described elsewhere). ${ }^{51}$ Interviewers used an adaptation of the Structured Clinical Interview (SCID-I) to assess a range of psychiatric disorders, including alcohol abuse/dependence, generalized anxiety disorder (GAD), lifetime MDD, and panic disorder according to DSM-IV-R criteria. Individuals were classified according to standard DSM-IV-R criteria with some exceptions. ${ }^{63,64}$ 


\section{Statistical Analyses}

Participants were categorized into one of two groups (weight stable or weight unstable) based on their retrospective silhouette selections for actual size during childhood, adolescence, and adulthood. Individuals who changed two silhouettes or fewer for all three time periods were classified as weight stable, and individuals who changed three silhouettes or more in at least one of the three time periods were classified as weight unstable. Criteria for weight stability versus instability were determined by examining how level of silhouette change (e.g. two vs. three silhouettes) related to a variable assessing number times individuals had lost and regained at least $10 \mathrm{lbs}$. These criteria were initially developed in the female subsample, as this group was analyzed first (and the topic of weight cycling has been studied more within female samples). Among women, individuals who changed three silhouettes or more reported greater weight loss and regain (10 lbs or more, $p<.05$ ). These criteria were subsequently applied to the male subsample, so that analyses were consistent across sexes.

Before testing the main hypotheses, descriptive statistics examining the frequency of different levels of weight instability were calculated (Table 1). Relations between weight instability and other variables that might influence weight fluctuation (e.g. number of pregnancies and live births, and smoking) were explored using Pearson product moment correlations (Table 2).

Logistic regressions examined the association between demographic, health, and psychological variables (independent) and weight instability (dependent variable). Analyses were conducted using Mplus version 4.1. ${ }^{65}$ Data were clustered by family number to control variability associated with individuals' twin status. An MLR estimator (maximum likelihood with robust standard errors) was used rather than maximum likelihood estimation because it is more robust with nonindependent and non-normal data. ${ }^{65}$

\section{Results}

\section{Participants}

Participation was predicted by female sex (odds ratio $[\mathrm{OR}]=2.14 . p<.0001$ ), older age (OR $=1.22, p<.0001)$, greater education $(\mathrm{OR}=1.12, p<.0001)$, and monozygosity $(\mathrm{OR}=1.47$, $p<.0001) .{ }^{61}$ Women's mean age was $37.8(\mathrm{SD}=8.16)$ years and their mean BMI was 25.8 $(\mathrm{SD}=6.02) \mathrm{kg} / \mathrm{m}^{2}$; men's mean age was 37.74 (SD 54.51 ) years and their mean BMI was 26.98 (SD 59.11 ) $\mathrm{kg} / \mathrm{m}^{2}$. Participants' BMI was categorized based on the criteria used by the World Health Organization (WHO). These categories include underweight (BMI below $18.5 ; 1.9 \%$ women, $0.7 \%$ men in the current sample), normal weight (BMI between 18.5 and 24.99; 52.9\% women, 32.0\% men), overweight (BMI between 25 and 29.99; 24.2\% women, $44.9 \%$ men), and obese (BMI of 30 and above; $19.1 \%$ women, $19.2 \%$ men).

\section{Primary Analyses}

Logistic regressions were conducted to address the hypothesis that weight instability would be positively associated with health limitations, body dissatisfaction, disinhibition, hunger, restraint, and BED, and negatively associated with health attitudes and self-esteem. We used 
a clustered design (grouped by family number) to control for variance associated with shared genetic contributions of participants' twin status. Five separate models were examined with weight instability as the dependent variable (coded as weight stable or weight unstable). Predictors were grouped into the following models: (1) drive for thinness, body dissatisfaction, and self-esteem, (2) restraint, disinhibition, hunger, and combined eating disorder diagnoses, (3) health limitations, health attitudes, and sick days taken from work, (4) noneating disorder psychiatric diagnoses (i.e., alcohol abuse, alcohol dependence, GAD, panic, and lifetime MDD), and (5) noneating disorder psychiatric diagnoses while controlling for presence of any history of binge eating (i.e., alcohol abuse, alcohol dependence, GAD, panic, lifetime MDD). Due to the sparseness of data for individual eating disorder diagnoses (i.e., AN, BN, BED), all eating disorder diagnoses were combined into a single dichotomous variable. Further, because of sparseness of data for BED diagnoses, lifetime binge eating was substituted for BED in the fifth model which evaluated the association between psychiatric disorders and weight instability while controlling for binge eating. Table 3 includes standardized coefficients, standard error, odds ratios, $z$ scores, and $p$ values for each of the variables.

For women, a test of the first model identified significant effects $(-2$ Loglikelihood $=$ -774.25) for both body dissatisfaction and self-esteem, with no effect for drive for thinness. For men, significant effects were found $(-2 \operatorname{Loglikelihood}=-702.19)$ for both body dissatisfaction and self-esteem; drive for thinness was non-significant.

The second model (examining eating behaviors) showed significant effects ( -2 Loglikelihood $=-749.31$ ) for disinhibition and the combined eating disorder diagnoses variable in the female sample; results were non-significant for restraint and hunger. No significant effects were found for any of the variables within the male sample $(-2$ Loglikelihood $=-75.73$ ).

Within the female sample, the third model revealed a significant effect $(-2$ Loglikelihood $=$ -721.92) for general attitudes about health, although findings were non-significant for health limitations and sick days taken from work in the past year. Within the male sample, there was also a significant effect $(-2$ Loglikelihood $=-721.92)$ for general attitudes about health, with non-significant findings for health limitations and sick days taken from work in the past year.

The fourth model revealed significant effects $(-2$ Loglikelihood $=-767.09)$ for lifetime MDD, GAD, and alcohol abuse in women. Women with lifetime MDD or GAD were more likely to be weight unstable. Conversely, women with a diagnosis of alcohol abuse were more likely to be weight stable. Results were non-significant for all other diagnoses.

The fifth model included all predictors from the fourth model and, in addition, examined the effect of binge eating on endorsement of psychiatric diagnoses among women. Results indicated a significant effect $(-2$ Loglikelihood $=-746.73)$ of binge eating on weight instability. If individuals endorsed binge eating, they were more likely to be classified as weight unstable. However, lifetime MDD remained significantly associated with weight instability when binge eating was included in the model. This suggests that women's 
endorsement of depressive symptomatology has an effect on weight instability independent of binge eating. In contrast, both GAD and alcohol abuse were no longer significant when binge eating was included in the model.

For men, a test of the fourth model (examining psychiatric diagnoses not accounting for binge eating) failed to identify any significant effects ( -2 Loglikelihood $=-718.17)$; thus, the fifth model was not tested among men because there were no associations between weight instability and psychiatric diagnoses.

\section{Discussion}

The current study examined correlates of self-reported weight instability over the lifespan in a population-based sample of women and men. Overall, results showed that weight unstable women were more likely to meet criteria for life-time MDD, GAD, and eating disorders.

Weight stable women were more likely to abuse alcohol. However, two of these associations (e.g. weight instability and GAD and weight stability and alcohol abuse) became nonsignificant once lifetime binge eating was accounted for, indicating that these forms of psychopathology are more strongly related to binge eating than weight instability itself. No associations between weight stability and psychiatric diagnoses were found in men. Results also indicated that weight instability was related to lower health satisfaction and self-esteem, and higher body dissatisfaction, dieting, and binge eating across sexes.

These findings differ from those of previous research, ${ }^{2}$ which has generally indicated that, among women, weight cycling was not associated with depressive symptoms when binge eating was taken into account. One possible explanation for this difference could be that the current study examined lifetime MDD, whereas others ${ }^{2}$ assessed current depressive symptomatology. Thus, among women, there may be a long-term relationship between weight instability and depressive symptoms that is not evident in studies examining transient depressive symptoms.

Results for both women and men are consistent with those of previous research ${ }^{30,39,66,67}$ identifying associations among body dissatisfaction, self-esteem, and obesity. Specifically, for both men and women in the current study, weight instability was associated with higher body dissatisfaction and lower self-esteem. Further, weight unstable women reported greater eating disinhibition and were also more likely to meet diagnostic criteria for an eating disorder than were weight stable women. Such associations were not identified among men. The sex differences in the relation between weight stability and eating disorder status are not surprising given the greater prevalence of eating pathology in women compared with men. ${ }^{68,69}$ Although weight instability was associated with body dissatisfaction in men, it appears that these negative attitudes were not related to disordered eating. Longitudinal research is needed to examine the specific attitudinal and behavioral antecedents and consequences of weight cycling across sexes.

Results of the current study also indicate that for both men and women, weight instability is associated with poorer health satisfaction, but is not related to perceived health limitations or number of sick days taken from work. Such results are similar to those of Venditti et al. ${ }^{6}$ and 
Lahti-Kioski et al., ${ }^{2}$ which indicated an association between weight cycling and poorer perceived physical health. However, unlike the current study, Lahti-Kioski et al. ${ }^{2}$ also found an association between weight cycling and number of sick days taken from work. Current results should be replicated before more definitive conclusions can be drawn, as factors other than perceived health can influence sick days taken, including cultural and socioeconomic issues.

Results of this study should be considered in light of its strengths and limitations. Strengths include the examination of weight patterns over the lifespan, rather than focusing on the effects of weight change occurring within a limited time period. This study also utilized a population-based sample of both women and men and extended previous research focused on clinical samples. Moreover, broader criteria were used to examine weight instability (by examining silhouette shifts), which could be more inclusive of individuals who have previously not been included in research on weight cycling.

Nonetheless, there are limitations to this study that should be noted. One limitation is that weight cycling episodes were not examined directly, as silhouettes assessed patterns of weight change over time. Therefore, findings might not apply directly to individuals whose weight cycles rapidly. In addition, because of the small number of individuals meeting full BED criteria, it was not possible to include this variable in the analyses. Future research should further examine whether endorsement of psychiatric symptoms is dependent on BED diagnostic status within a population-based sample. The study was also cross-sectional, with retrospective reports of child and adolescent silhouettes; thus it is not possible to infer causal relationships between weight instability and its correlates. Although weight instability might put individuals at risk for outcomes like increased body dissatisfaction and lower selfesteem, it is also plausible that these factors could initiate weight instability as individuals attempt to lose weight to enhance their feelings of self-worth. Further, although data on height and weight in adulthood were available, we did not have such data for childhood and adolescence. Thus, it cannot be assumed that silhouette selections reflect actual weight change patterns over the lifespan. Finally, participants in this study were exclusively White, and results might generalize to other racial or ethnic groups. Future research should attempt to replicate the current study in samples including individuals of different ethnic/racial backgrounds. Research could also examine more specific medical outcomes that might be related to weight instability that were not examined in this study.

\section{Acknowledgments}

Supported by MH-068520 (to S.E.M.), MH-20030 (to K.S.M.), and MH-01553 (to C.M.B.).

\section{References}

1. National Task Force on the Prevention and Treatment of Obesity. . Weight cycling. JAMA. 1994; 272:1196-1202. [PubMed: 7741844]

2. Lahti-Koski M, Mannisto S, Pietinen P, Vartiainen E. Prevalence of weight cycling and its relation of health indicators in Finland. Obes Res. 2005; 13:333-341. [PubMed: 15800292]

3. Field AE, Byers T, Hunter DJ, Laird NM, Manson JE, Williamson DF, et al. Weight cycling, weight gain, and risk of hypertension in women. Am J Epidemiol. 1999; 150:573-579. [PubMed: 10489996] 
4. Field AE, Wing RR, Manson JE, Spiegelman DL, Willett WC. Relationship of a large weight loss to long-term weight change among young and middle-aged US women. Int J Obes Relat Metab Disord. 2001; 25:1113-1121. [PubMed: 11477495]

5. Field AE, Manson JE, Taylor CB, Willett WC, Colditz GA. Association of weight change, weight control practices, and weight cycling among women in the Nurses' Health Study II. Int J Obes Relat Metab Disord. 2004; 28:1134-1142. [PubMed: 15263922]

6. Venditti EM, Wing RR, Jakicic JM, Butler BA, Marcus MD. Weight cycling, psychological health, and binge eating in obese women. J Consult Clin Psychol. 1996; 64:400-405. [PubMed: 8871424]

7. Kroke A, Liese AD, Bergmann MM, Klipstein-Grobusch K, Hoffmann K, Boeing H. Recent weight changes and weight cycling as predictors of subsequent two year weight change in a middle-aged cohort. Int J Obes. 2002; 26:403-409.

8. Giusti V, Heraief E, Gaillard RC, Burckhardt P. Predictive factors of binge eating disorder in women searching to lose weight. Eat Weight Disord. 2004; 9:44-49. [PubMed: 15185833]

9. Field AE, Manson JE, Laird N, Williamson DF, Willett WC, Colditz GA. Weight cycling and the risk of developing type 2 diabetes among adult women in the United States. Obes Res. 2004; 12:267-274. [PubMed: 14981219]

10. Simkin-Silverman LR, Wing RR, Plantinga P, Matthews KA, Kuller LH. Lifetime weight cycling and psychological health in normal-weight and overweight women. Int J Eat Disord. 1998; 24:175-183. [PubMed: 9697016]

11. Foster GD, Sarwer DB, Wadden TA. Psychological effects of weight cycling in obese persons: A review and research agenda. Obes Res. 1997; 5:474-488. [PubMed: 9385625]

12. Brownell KD. Whether obesity should be treated. Health Psychol. 1993; 12:339-341. [PubMed: 8223356]

13. Spitzer RL, Devlin M, Walsh BT, Hasin D, Wing R, Marcus M, et al. Binge eating disorder: A multisite field trial of the diagnostic criteria. Int J Eat Disord. 1992; 11:191-203.

14. Heatherton TF, Mahamedi F, Striepe M, Field AE, Keel P. A 10-year longitudinal study of body weight, dieting, and eating disorder symptoms. J Abnorm Psychol. 1997; 106:117-125. [PubMed: 9103723]

15. Thompson JK, Coovert MD, Stormer SM. Body image, social comparison, and eating disturbance: A covariance structure modeling investigation. Int J Eat Disord. 1999; 26:43-51. [PubMed: 10349583]

16. Rodin J, Silberstein L, Striegel-Moore R. Women and weight: A normative discontent. Nebr Symp Motiv. 1984; 32:267-307. [PubMed: 6398857]

17. Rozin P, Trachtenberg S, Cohen AB. Stability of body image and body image dissatisfaction in American college students over about the last 15 years. Appetite. 2001; 37:245-248. [PubMed: 11895325]

18. Gendall KA, Bulik CM, Sullivan PF, Joyce PR, McIntosh VV, Carter FA. Body weight in bulimia nervosa. Eat Weight Disord. 1999; 4:157-164. [PubMed: 10728175]

19. Mitchell JE, Pyle RL, Eckert E, Hatsukami D, Soll E. Bulimia nervosa with and without a history of overweight. J Subst Abuse. 1990; 2:369-374. [PubMed: 2136121]

20. Lissner L, Odell PM, D’Agostino RB, Stokes J III, Kreger BE, Belanger AJ, et al. Variability of body weight and health outcomes in the Framingham population. N Engl J Med. 1991; 324:18391844. [PubMed: 2041550]

21. Folsom AR, Prineas RJ, Kaye SA, Soler JT. Body fat distribution and self-reported prevalence of hypertension, heart attack, and other heart disease in older women. Int J Epidemiol. 1989; 18:361367. [PubMed: 2767849]

22. Iribarren C, Sharp DS, Burchfiel CM, Petrovitch H. Association of weight loss and weight fluctuation with mortality among Japanese American men. N Engl J Med. 1995; 333:686-692. [PubMed: 7637745]

23. Blair SN, Shaten J, Brownell K, Collins G, Lissner L. Body weight change, all-cause mortality, and cause-specific mortality in the Multiple Risk Factor Intervention Trial. Ann Intern Med. 1993; 119:749-757. [PubMed: 8363210] 
24. National Task Force on the Prevention and Treatment of Obesity. Dieting and the development of eating disorders in overweight and obese adults. Arch Intern Med. 2000; 160:2581-2589. [PubMed: 10999971]

25. Bartlett SJ, Wadden TA, Vogt RA. Psychosocial consequences of weight cycling. J Consult Clin Psychol. 1996; 64:587-592. [PubMed: 8698953]

26. World Health Organization. Diet, Nutrition and the Prevention of Chronic Disease. Report of a Joint WHO/FAO Expert Consultation. World Health Organization; Geneva, Switzerland: 2003. WHO Technical Report Series 916

27. Henderson, KE.; Brownell, KD. The toxic enviornment and obesity: Contribution and cure. In: Thompson, JK., editor. Handbook of Eating Disorders and Obesity. John Wiley and Sons; Hoboken, NJ: 2004. p. 339-348.

28. Kennett DJ, Nisbet C. The influence of body mass index and learned resourcefulness skills on body image and lifestyle practices. Patient Educ Couns. 1998; 33:1-12. [PubMed: 9481344]

29. Friedman MA, Brownell KD. Psychological correlates of obesity: Moving to the next research generation. Psychol Bull. 1995; 117:3-20. [PubMed: 7870862]

30. Angle S, Keskinen S, Lapinleimu H, Helenius H, Raittinen P, Ronnemaa T, et al. Weight gain since infancy and prepubertal body dissatisfaction. Arch Pediatr Adolesc Med. 2005; 159:567571. [PubMed: 15939857]

31. Pesa JA, Syre TR, Jones E. Psychosocial differences associated with body weight among female adolescents: The importance of body image. J Adolesc Health. 2000; 26:330-337. [PubMed: 10775825]

32. Neumark-Sztainer, D.; Haines, J. Psychosocial and behavioral consequences of obesity. In: Thompson, JK., editor. Handbook of Eating Disorders and Obesity. John Wiley \& Sons, Inc.; Hoboken, NJ: 2004. p. 349-371.

33. Kansi J, Wichstrom L, Bergman LR. Eating problems and the self-concept: Results based on a representative sample of norwegian adolescent girls. J Youth Adolesc. 2003; 32:325-335.

34. Johansen SN, Jacobsen H, Rosenvinge JH, Perry JA, Silvera DH. Eating pattern and self-esteem in overweight women. Eat Weight Disord. 1998; 3:33-36. [PubMed: 11234252]

35. Ghaderi A. Structural modeling analysis of prospective risk factors for eating disorder. Eat Behav. 2003; 3:387-396. [PubMed: 15000998]

36. Friestad C, Rise J. A longitudinal study of the relationship between body image, self-esteem and dieting among 15-21 year olds in Norway. Eur Eat Disord Rev. 2004; 12:245-255.

37. French SA, Story M, Perry CL. Self-esteem and obesity in children and adolescents: A literature review. Obes Res. 1995; 3:479-490. [PubMed: 8521169]

38. Crow S, Eisenberg ME, Story M, Neumark-Sztainer D. Psychosocial and behavioral correlates of dieting among overweight and non-overweight adolescents. J Adolesc Health. 2006; 38:569-574. [PubMed: 16635769]

39. Cohen DL, Petrie TA. An examination of psychosocial correlates of disordered eating among undergraduate women. Sex Roles. 2005; 52:29-42.

40. Calam R, Waller G. Are eating and psychosocial characteristics in early teenage years useful predictors of eating characteristics in early adulthood? A 7-year longitudinal study. Int J Eat Disord. 1998; 24:351-362. [PubMed: 9813760]

41. Button EJ, Loan P, Davies J, Sonuga-Barke EJ. Self-esteem, eating problems, and psychological well-being in a cohort of schoolgirls aged 15-16: A questionnaire and interview study. Int J Eat Disord. 1997; 21:39-47. [PubMed: 8986516]

42. Marchesini G, Cuzzolaro M, Mannucci E, Dalle Grave R, Gennaro M, Tomasi F, et al. Weight cycling in treatment-seeking obese persons: data from the QUOVADIS study. Int J Obes Relat Metab Disord. 2004; 28:1456-1462. [PubMed: 15314631]

43. Kensinger GJ, Murtaugh MA, Reichmann SK, Tangney CC. Psychological symptoms are greater among weight cycling womenwith severe binge eating behavior. J Am Diet Assoc. 1998; 98:863868. [PubMed: 9710655]

44. Portier K, Keith Tolson J, Roberts SM. Body weight distributions for risk assessment. Risk Anal. 2007; 27:11-26. [PubMed: 17362397] 
45. Williamson PS, Levy BT. Long-term body weight fluctuation in an overweight population. Int J Obes. 1988; 12:579-583. [PubMed: 3235274]

46. Thompson JK, Altabe M, Johnson S, Stormer SM. Factor analysis of multiple measures of body image disturbance: Are we all measuring the same construct? Int J Eat Disord. 1994; 16:311-315. [PubMed: 7833967]

47. Tehard B, van Liere MJ, Com Nougué C, Clavel-Chapelon F. Anthropometric measurements and body silhouette of women: Validity and perception. J Am Diet Assoc. 2002; 102:1779-1784. [PubMed: 12487540]

48. Stunkard AJ, Sorensen T, Schulsinger F. Use of a Danish adoption register for the study of obesity and thinness. Res Publ Assoc Res Nerv Ment Dis. 1983; 60:115-120. [PubMed: 6823524]

49. Bulik CM, Wade TD, Heath AC, Martin NG, Stunkard AJ, Eaves LJ. Relating body mass index to figural stimuli: population-based normative data for Caucasians. Int J Obes Relat Metab Disord. 2001; 25:1517-1524. [PubMed: 11673775]

50. Must A, Spadano J, Coakley EH, Field AE, Colditz G, Dietz WH. The disease burden associated with overweight and obesity. JAMA. 1999; 282:1523-1529. [PubMed: 10546691]

51. Kendler KS, Prescott CA. A population-based twin study of life-time major depression in men and women. Arch Gen Psychiatry. 1999; 56:39-44. [PubMed: 9892254]

52. Garner D, Olmsted M, Polivy J. Development and validation of a multidimensional eating disorder inventory for anorexia nervosa and bulimia. Int J Eat Disord. 1983; 2:15-35.

53. Stunkard AJ, Messick S. Three-factor eating questionnaire to measure dietary restraint, disinhibition, and hunger. J Psychosom Res. 1985; 29:71-83. [PubMed: 3981480]

54. Stunkard, AJ.; Messick, S. Eating Inventory Manual. Psychological Assessment Resources; San Antonio: 1988.

55. Mazzeo SE, Aggen SH, Anderson C, Tozzi F, Bulik CM. Investigating the structure of the eating inventory (three-factor eating questionnaire): A confirmatory approach. Int J Eat Disord. 2003; 34:255-264. [PubMed: 12898563]

56. First, M.; Spitzer, RL.; Gibbon, M.; Williams, JB. Structured Clinical Interview for DSM-IV Axis I Disorders (SCID-I), Clinician Version. American Psychiatric Press; Washington, DC: 1997.

57. American Psychiatric Association. Diagnostic and Statistical Manual of Mental Disorders. 4th ed (text-revision). American Psychiatric Association; Washington, DC: 2000.

58. Mazzeo SE, Slof-Op't Landt MC, Jones I, Mitchell K, Kendler KS, Neale MC, et al. Associations among postpartum depression, eating disorders, and perfectionism in a population-based sample of adult women. Int J Eat Disord. 2006; 39:202-211. [PubMed: 16498586]

59. Rosenberg, M. Society and the Adolescent Self-Image. Princeton University Press; Princeton, NJ: 1965.

60. Crow S, Eisenberg ME, Story M, Neumark-Sztainer D. Psychosocial and behavioral correlates of dieting among overweight and non-overweight adolescents. J Adolesc Health. 2006; 38:569-574. [PubMed: 16635769]

61. Slof R, Mazzeo S, Bulik CM. Characteristics of women with persistent thinness. Obes Res. 2003; 11:971-977. [PubMed: 12917502]

62. Mazzeo SE, Slof RM, Tozzi F, Kendler KS, Bulik CM. Characteristics of men with persistent thinness. Obes Res. 2004; 12:1367-1369. [PubMed: 15483200]

63. Kendler KS, Gardner CO, Prescott CA. Panic syndromes in a population-based sample of male and female twins. Psychol Med. 2001; 31:989-1000. [PubMed: 11513384]

64. Kendler KS, Myers J, Prescott CA, Neale MC. The genetic epidemiology of irrational fears and phobias in men. Arch Gen Psychiatry. 2001; 58:257-265. [PubMed: 11231833]

65. Muthén, LK.; Muthén, BO. Mplus User's Guide. 4th ed.. Muthén \& Muthén; Los Angeles: 1998-2006.

66. Wadden TA, Bartlett S, Letizia KA, Foster GD, Stunkard AJ, Conill A. Relationship of dieting history to resting metabolic rate, body composition, eating behavior, and subsequent weight loss. Am J Clin Nutr. 1992; 56(1 Suppl):203S-8S. [PubMed: 1615885]

67. Wardle J, Cooke L. The impact of obesity on psychological well-being. Best Pract Res Clin Endocrinol Metab. 2005; 19:421-440. [PubMed: 16150384] 
68. Kessler RC, Berglund P, Chiu WT, Demler O, Heeringa S, Hiripi E, et al. The National Comorbidity Survey Replication (NCS-R): Design and field procedures. Int J Methods Psychiatr Res. 2004; 13:69-92. [PubMed: 15297905]

69. Kessler RC, Chiu WT, Demler O, Merikangas KR, Walters EE. Prevalence, severity, and comorbidity of 12-month DSM-IV disorders in the National Comorbidity Survey Replication. Arch Gen Psychiatry. 2005; 62:617-627. [PubMed: 15939839] 
TABLE 1

Percentage of weight instability, means (SDs), or percentages for all variables for weight stable and unstable groups

\begin{tabular}{|c|c|c|c|c|}
\hline \multirow{3}{*}{$\begin{array}{l}\text { Weight Instability } \\
\text { Variable }\end{array}$} & \multicolumn{2}{|c|}{ Women $(N=1,510)$} & \multicolumn{2}{|c|}{$\operatorname{Men}(N=1,111)$} \\
\hline & \multicolumn{2}{|c|}{$26,2 \%$} & \multicolumn{2}{|c|}{$40,6 \%$} \\
\hline & Stable $(N=1,108)$ & Unstable $(N=393)$ & Stable $(N=650)$ & Unstable $(N=451)$ \\
\hline BMI $\left(\mathrm{kg} / \mathrm{m}^{2}\right)$ & $24,68(5,37)$ & $29,00(6,60)$ & $26,08(4,28)$ & $28,31(4,52)$ \\
\hline Drive for thinness & $20,03(7.31)$ & $22,54(7,64)$ & $17,65(3,49)$ & $17,11(3,74)$ \\
\hline Body dissatisfaction & $35,87(10,6)$ & $41,57(9,74)$ & $35,76(3,63)$ & $36,88(3,94)$ \\
\hline Self-esteem & $22,71(4,52)$ & $21,41(4,78)$ & $20,96(3,70)$ & $20,37(3,74)$ \\
\hline Restraint & $24,47(5,06)$ & $24,26(5,02)$ & $23,77(4,68)$ & $22,50(4,67)$ \\
\hline Disinhibition & $21,67(5,71)$ & $24,58(7,18)$ & $21,11(5,15)$ & $22,57(5,74)$ \\
\hline Hunger & $15,93(4,33)$ & $17,69(5,88)$ & $15,61(4,29)$ & $16,28(4,93)$ \\
\hline Health satisfaction & $3,49(0,68)$ & $3,30(0,72)$ & $3,41(0,72)$ & $3,26(0,76)$ \\
\hline Health limitations & $1,25(0,65)$ & $1,33(0,74)$ & $1,25(0,66)$ & $1,32(0,72)$ \\
\hline Sick days (last year) & $2,06(1,21)$ & $2,15(1,25)$ & $1,77(0,98)$ & $1,77(1,13)$ \\
\hline Any diet (lifetime) & $58,50 \%$ & $22,60 \%$ & $27,70 \%$ & $25,10 \%$ \\
\hline Any binge (lifetime) & $12,20 \%$ & $8,00 \%$ & $7,30 \%$ & $8,20 \%$ \\
\hline Any eating disorder & $4,70 \%$ & $3,70 \%$ & $8,20 \%$ & $8,80 \%$ \\
\hline AN narrow & $1,60 \%$ & $0,30 \%$ & $a$ & $a$ \\
\hline AN broad & $9,70 \%$ & $2,70 \%$ & $0,30 \%$ & $0,10 \%$ \\
\hline $\mathrm{BN}$ narrow & $9,60 \%$ & $4,40 \%$ & $1,80 \%$ & $1,20 \%$ \\
\hline BN broad & $25,20 \%$ & $18,10 \%$ & $8,20 \%$ & $7,10 \%$ \\
\hline BED narrow & $9,70 \%$ & $7,00 \%$ & $0,20 \%$ & $0,50 \%$ \\
\hline BED broad & $12,00 \%$ & $10,20 \%$ & $0,30 \%$ & $0,70 \%$ \\
\hline Alcohol dependence & $6,50 \%$ & $2,50 \%$ & $12,40 \%$ & $12,00 \%$ \\
\hline Alcohol abuse & $10,60 \%$ & $3,10 \%$ & $18,60 \%$ & $16,10 \%$ \\
\hline Panic & $8,30 \%$ & $3,80 \%$ & $3,10 \%$ & $3,20 \%$ \\
\hline Phobia & $20,60 \%$ & $8,00 \%$ & $11,90 \%$ & $10,50 \%$ \\
\hline MDD & $25,10 \%$ & $11,40 \%$ & $16,40 \%$ & $12,50 \%$ \\
\hline GAD & $1,70 \%$ & $1,50 \%$ & $0,90 \%$ & $0,60 \%$ \\
\hline
\end{tabular}

Notes: Drive for thinness; body dissatisfaction = EDI; self-esteem = Rosenberg self-esteem scale; restraint = TFEQ restraint; disinhibition $=$ TFEQ disin-hibition: hunger $=$ TFEQ hunger.

${ }^{a}$ No men in either weight stable or unstable groups met criteria for AN Narrow. 
TABLE 2

\section{Correlations between continuous variables for women and men}

\begin{tabular}{|c|c|c|c|c|c|c|c|c|}
\hline & BMI & Self-Esteem & Restraint & Disinhibition & Hunger & Drive for Thinness & Body Dissatisfaction & Weight $L / R$ \\
\hline BMI & 1.00 & $-0.13^{*}$ & $-0.08^{*}$ & $0.44^{*}$ & $0.31^{*}$ & $0.26^{*}$ & $0.51^{*}$ & $0.36^{*}$ \\
\hline Self-esteem & -0.05 & 1.00 & $0.07^{*}$ & $-0.22^{*}$ & $-0.21^{*}$ & $-0.19^{*}$ & $-0.22^{*}$ & $-0.08^{*}$ \\
\hline Restraint & $-0.16^{*}$ & 0.07 & 1.00 & 0.01 & -0.03 & $0.44^{*}$ & $0.13^{*}$ & $0.07^{*}$ \\
\hline Disinhibition & $0.28^{*}$ & $-0.14^{*}$ & -0.03 & 1.00 & $0.78^{*}$ & $0.55^{*}$ & $0.55^{*}$ & $0.43^{*}$ \\
\hline Hunger & $0.15^{*}$ & $-0.14^{*}$ & -0.07 & $0.78^{*}$ & 1.00 & $0.46^{*}$ & $0.41^{*}$ & $0.30^{*}$ \\
\hline Drive for thinness & 0.04 & -0.02 & $0.52^{*}$ & $0.23^{*}$ & $0.22^{*}$ & 1.00 & $0.60^{*}$ & $0.28^{*}$ \\
\hline Body dissatisfaction & $0.22^{*}$ & 0.03 & $-0.13^{*}$ & 0.05 & -0.03 & $-0.28^{*}$ & 1.00 & $0.32^{*}$ \\
\hline Weight L/R & $0.27^{*}$ & -0.04 & 0.05 & $0.20^{*}$ & $0.13^{*}$ & $0.19^{*}$ & 0.04 & 1.00 \\
\hline
\end{tabular}

Notes: Correlations for women $(N=1,510)$ appear above the diagonal; correlations for men $(N=1,111)$ appear below the diagonal. BMI $=$ body mass index; weight $\mathrm{L} / \mathrm{R}=$ number of times lost $10 \mathrm{lbs}$. and gained it back.

* $p<.01$. 


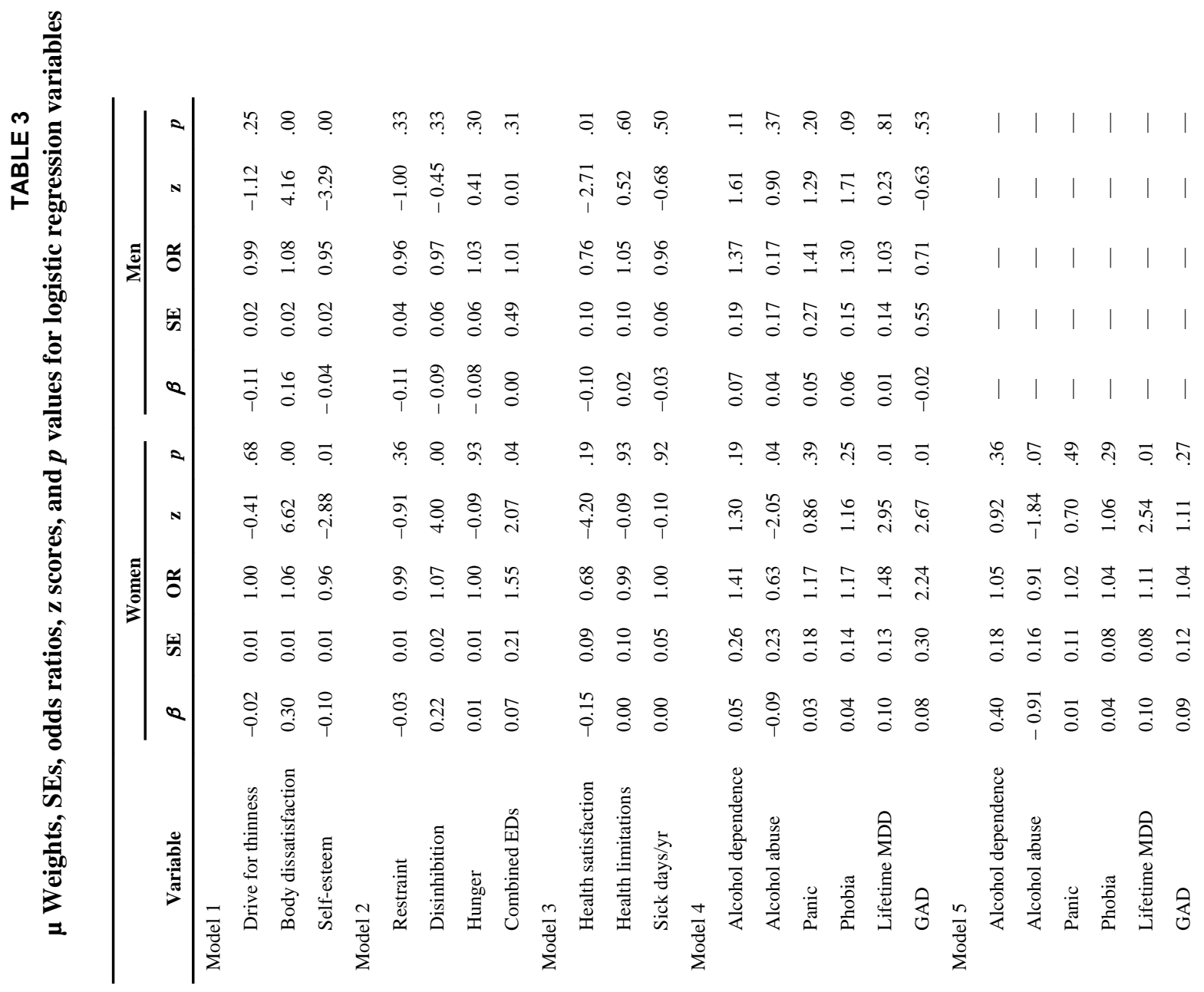




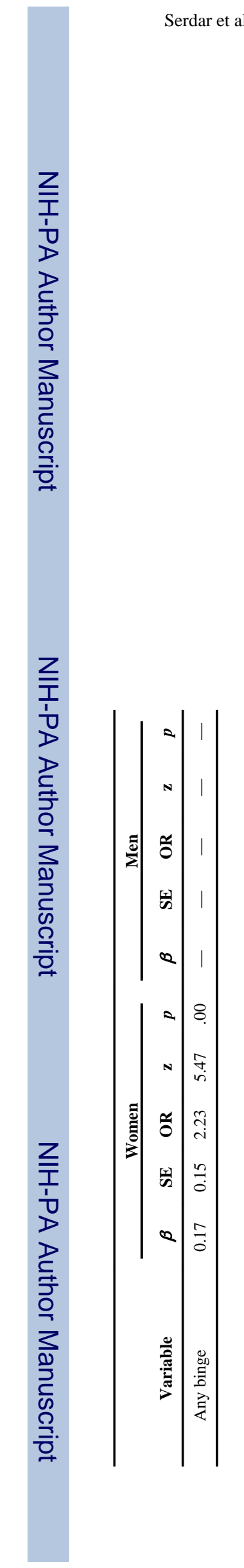

Page 17

Int J Eat Disord. Author manuscript; available in PMC 2014 May 22. 